\title{
Lomba Kreativitas Tanaman Hidroponik sebagai Strategi dalam Mewujudkan Kampung Hijau di RW 09 Kelurahan Kebon Pala Kota Administrasi Jakarta
} Timur

\author{
Ulinata1, Grace Putri Dianty², Ajeng ED Hasugian³, Enrique K Kidingallo ${ }^{4}$ \\ 1, 2, 3, 4 Universitas Kristen Indonesia, Jakarta, Indonesia \\ E-mail: ulinata@uki.ac.id; gdianty@gmail.com; ajengevita1@gmail.com; \\ ekidingallo@gmail.com
}

\begin{abstract}
Abstrak
Untuk dapat mewujudkan kampung hijau secara perlahan dan mencapai kondisi masyarakat yang hidup sehat terutama pada masa Pandemik COVID 19, serta meningkatkan ketahanan pangan bagi masyarakat yang memiliki keterbatasan lahan, maka hidroponik merupakan pilihan yang tepat. Program Studi Arsitektur Fakultas Teknik UKI melalui program Pengabdian Pada Masyarakat melakukan kegiatan Green Action 22 Lomba Kreativitas Tanaman Hidroponik sebagai Strategi dalam Mewujudkan Kampung Hijau di RW 09 Kelurahan Kebon Pala Kota Administrasi Jakarta Timur 2020. Metode yang dilakukan adalah mengadakan lomba kreasi tanaman hidroponik untuk menggiatkan kembali kegiatan berkreasi menanam khususnya hidroponik sehingga perlahan akan dapat meningkatkan ketahanan pangan dan mewujudkan kampung hijau di kelurahan Kebon Pala tersebut. Prosesnya menyiapkan alat dan bahan yang akan dipergunakan pada saat lomba berupa stereofoam, dua botol nutrisi $A B$ mix, pembolong, selang, netpot, airator, flanel potong, rockwool, benih selada, samhong, TDS, nampan, gelas ukur yang dibagikan kepada para peserta lomba. Waktu perlombaan sekitar 5-6 minggu. Hasilnya adalah pada saat pengumuman pemenang, peserta wajib menunjukkan hasil panen yang sudah dikemas. Kategori pemenang berdasarkan empat kriteria diantaranya tingkat kerapian alat dan media tanam, perkembangan benih, bobot panen yang dihasilkan kemasannya. Selain hadiah, para peserta juga memperoleh edukasi mengenai hidroponik.
\end{abstract}

Kata Kunci: Green Action, Hidroponik, Kebon Pala

\begin{abstract}
To create green villages and achieve conditions for people who live healthy, especially during the COVID-19 Pandemic, as well as increase food security for people who have limited land, hydroponics is the right choice. Architecture Study Program of Faculty of Enginering Universitas Kristen Indonesi through the Community Service program conducted Green Action 22 Hydroponic Plant Creativity Contest as a Strategy in Creating a Green Village in RW 09 Kebon Pala Village, East Jakarta Administration City 2020. The method used is to hold a hydroponic plant creation competition to reactivate creative planting activities, especially hydroponics so that it will slowly increase food security and create a green village in the Kebon Pala village. The process is to prepare tools and materials that will be used during the competition in the form of stereofoam, two bottles of $A B$ mix nutrition, tubing, hose, netpot, airator, cut flannel, rockwool, lettuce seeds, samhong, TDS, trays, measuring cups which are distributed to the competition participants. . The race time is around 5-6 weeks. The result is that when the winner is announced, the participant must show the packaged harvest. The winner categories are based on four criteria, including the level of neatness of
\end{abstract}


the planting medium and tools, seed development, harvest weight produced by the packaging. Apart from prizes, the participants also received education about hydroponics.

\section{Key words : Green Action, Hydroponic, Kebon Pala}

\section{PENDAHULUAN}

Hidroponik merupakan salah satu sistem budidaya tanpa menggunakan media tanah yang cocok diterapkan di wilayah yang memiliki lahan sempit[1]. Hidroponik juga memiliki manfaat diantaranya memperoleh jenis tanaman untuk hasil pangan yang dapat dikonsumsi sendiri maupun dijual untuk meningkatkan hasil ekonomi tanpa membutuhkan lahan yang luas[2]. Selain itu, hidroponik bisa memperindah tampilan luar rumah serta menjadi ruang hijau bagi rumah tersebut [3]. Hidroponik memiliki beberapa sistem yang cukup rumit, akan tetapi jika sudah dipahami akan terlihat sangat sederhana dan cukup mudah untuk melakukannya[4]. Namun sebagian masyarakat khususnya di Daerah Khusus lbukota (DKI) Jakarta belum begitu mengetahui bagaimana cara menanam tanaman hidroponik, salah satunya adalah di RW 09 Kelurahan Kebon Pala Kota Administrasi Jakarta Timur.

Untuk itulah dosen dan mahasiswa Program Studi Arsitektur Universitas Kristen Indonesia mengadakan Pengabdian kepada Masyarakat dengan judul Lomba Kreativitas Tanaman Hidroponik sebagai Strategi dalam Mewujudkan Kampung Hijau di Kelurahan kelurahan Kebon Pala Kota Administrasi Jakarta Timur Tahun 2020 agar masyarakat khususnya di RW 09

Kelurahan Kebon Pala memperoleh edukasi serta mampu untuk melakukan kegiatan menanam tanaman hidroponik di rumah masing-masing secara mandiri dan berkelanjutan.

Kelurahan Kebon Pala adalah sebuah kelurahan di Kecamatan Makasar, Jakarta Timur. Kelurahan ini memiliki penduduk sebesar 37.226 jiwa (desember 2008) dan luas wilayah 2, 29 km2. Kelurahan ini berbatasan dengan Kelurahan Cipinang Besar Selatan di sebelah utara, Kelurahan Halim Perdanakusuma dan Kelurahan Makasar di sebelah selatan, sebelah timur berbatasan dengan kelurahan Cipinang Melayu dan kelurahan Halim Perdanakusuma, di sebelah barat dengan kelurahan Cililitan dan kelurahan Cawang [5].

Di era Pandemic COVID 19 ini, masyarakat RW 09 Kelurahan Kebon Pala Kota Administrasi Jakarta Timur lebih banyak berdiam diri dirumah sehingga aktivitas pun berkurang. Padahal sebelum era COVID 19 masyarakat RW 09 Kelurahan Kebon Pala Kota Administrasi Jakarta Timur sebenarnya aktif dalam berkegiatan seperti kegiatan pemeliharaan lingkungan dan kesehatan, PKK dan lainnya. Kegiatan Pengabdian kepada 
Masyarakat yang berjudul Green Action22 Lomba Kreativitas Tanaman Hidroponik sebagai Strategi dalam Mewujudkan Kampung Hijau di Kelurahan Kebon Pala Kota Administrasi Jakarta Timur 2020 sehingga diharapkan dapat menggiatkan kembali kegiatan yang pernah ada di era sebelum COVID 19.

Kegiatan Pengabdian Pada Masyarakat ini terdiri dari beberapa rangkaian acara diantaranya Sosialisasi kepada masyarakat di RW 09 Kelurahan Kebon Pala Kota Administrasi Jakarta Timur, Penyuluhan mengenai tanaman hidroponik oleh narasumber, diskusi dengan masyarakat dan narasumber, lomba kreativitas tanaman hydroponik yang diikuti oleh masyarakat hingga penjurian dan pengumuman pemenang lomba. Kegiatan Pengabdian Pada Masyarakat ini melibatkan mahasiswa Program Studi Arsitektur Fakultas Teknik Universitas Kristen Indonesia Angkatan 2017 dan diharapkan mampu mengedukasi masyarakat mengenai tanaman hidroponik dan membangkitkan semangat masyarakat dalam mewujudkan kampung hijau yaitu dengan berkreasi dengan tanaman hidroponik.

\section{METODE}

Metode yang dipakai pada kegiatan Pengabdian Pada Masyarakat yang berjudul Green Action 22 Lomba Kreativitas Tanaman Hidroponik sebagai Strategi dalam Mewujudkan Kampung
Hijau di Kelurahan Kebon Pala Kota Administrasi Jakarta Timur 2020 adalah sebagai berikut:

\section{METODE PEMILIHAN LOKASI}

Penulis menentukan lokasipenelitian dimana lokasi ini telah dilakukan program sosialisasi dan workhshop mengenai pembuatan tanaman hidroponik di Kelurahan Kebon Pala Kota Administrasi Jakarta Timur yang diselenggarakan oleh Program Studi Arsitektur Fakultas Teknik Universitas Kristen Indonesia (UKI). Dikarenakan masih dalam kondisi Pandemik COVID 19, Penulis membatasi area lokasi Pengabdian pada Masyarakat berada di RW 09, Kelurahan Kebon Pala, Kota Administrasi Jakarta Timur agar tidak menimbulkan keramaian.

\section{METODE PELAKSANAAN}

Selanjutnya untuk menyusun laporan kegiatan ini digunakan metode pelaksanaan yang terdiri dari beberapa tahap yaitu:

1. Mengundang perwakilan di RW dengan masing-masing grup yang membuat 6 kelompok yang terdiri dari 2 orang untuk sosialisasi dan penyuluhan/tutorial untuk membuat tanaman hidroponik.

2. Membeli bahan dan alat-alat yang diperlukan dan dibagikan ke masingmasing peserta lomba untuk dipakai selama kegiatan lomba berlangsung

3. Melakukan lomba pembuatan tanaman hidroponik. 
4. Meninjau hasil tanaman hidroponik dalam kurun waktu 5 minggu serta mengumumkan pemenang dan membagikan hadiah pemenang.

Program Pengabdian Pada Masyarakat yang berjudul Green Action 22 Lomba Kreativitas Tanaman Hidroponik sebagai Strategi dalam Mewujudkan Kampung Hijau di Kelurahan Cawang dan Kelurahan Kebon Pala Kota Administrasi Jakarta Timur 2020 dilakukan di era pandemik COVID 19 ini tentu saja tetap memperhatikan protokol kesehatan. Pelaksanaan nya dilakukan oleh Dosen dan Mahasiswa Program Studi Arsitektur Fakultas Teknik Universitas kristen Indonesia.

\section{HASIL DAN PEMBAHASAN}

Lomba Kreativitas Tanaman Hidroponik ini diikuti oleh enam (6) kelompok dimana masing-masing kelompok terdiri dari satu (1) orang yang berasal dari RW 09 Kelurahan Kebon Pala Jakarta Timur. Panitia Pelaksana kegiatan Program Pengabdian pada masyarakat membeli alat-alat dan bahan terselebih dahulu untuk dibagikan kepada seluruh peserta nantinya. Alat-alat dan bahan tersebut adalah stereofoam, dua (2) botol nutrisi $A B$ mix, pembolong, selang, netpot, airator, flanel potong, rockwool, benih selada dan samhong, TDS, baki/nampan dan gelas ukur.

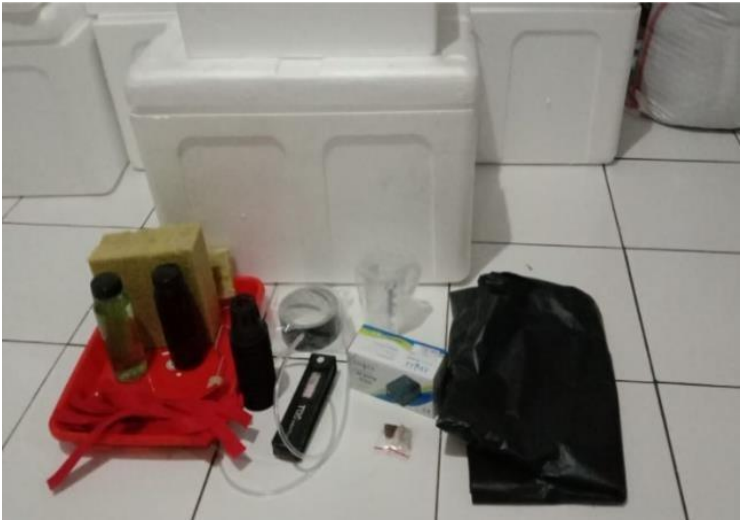

\section{Gambar 1. Alat-Alat dan Bahan yang Digunakan untuk Lomba}

Setelah alat-alat dan bahan dibeli, Panitia Pelaksana membagikan alat-alat dan bahan yang akan dipakai selama perlombaan berlangsung dua harisebelum acara lomba dimulai.

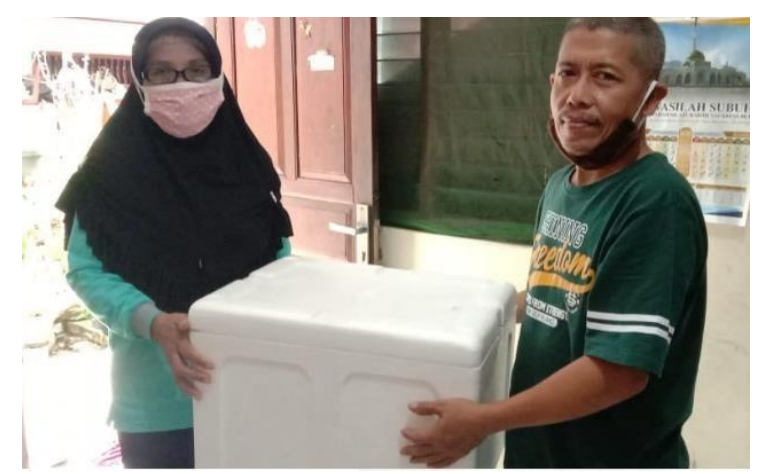

Gambar 2. Pembagian Alat-Alat dan Bahan ke Salah Satu Peserta Lomba

Setelah acara sosialisasi berlangsung, lomba pun dimulai dengan memastikan terlebih dahulu nama peserta yang akan mengikuti lomba dan telah menerima alat-alat dan bahan yang digunakan untuk lomba. Nama-nama peserta diantaranya adalah :

1. Irfan Firdaus

2. Muhamad ardianto

3. Djunaedi 
4. Yudi wahyudi

5. Suparmi

6. Mujiyono joko turyanto

Lomba dimulai pada tanggal 12 desember 2020 setelah sosialisasi berlangsung dengan syarat peserta harus mendokumentasikan dalam bentuk foto terkait perkembangan tanaman dari masing-masing peserta di tiap minggunya dalam kurun waktu 5-6 minggu ke depan.

Pada minggu pertama, benih disemai dalam rockwool dan dijemur di bawah panas matahari dengan menggunakan nampan/baki yang disediakan hingga muncul tunas daun. Kelembaban rockwool harus terjaga agar pertumbuhan tiap tanaman merata.

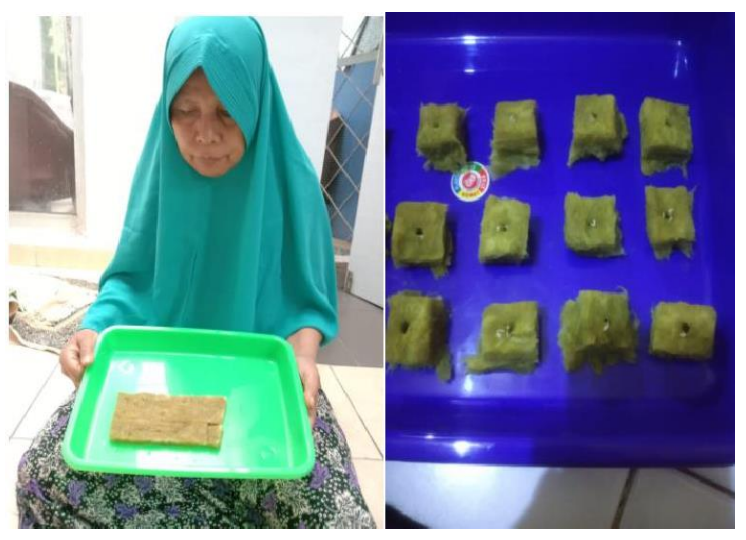

Gambar 3. Perkembangan Benih di Minggu Pertama Salah Satu Peserta Lomba

Pada Minggu kedua peserta mulai menyiapkan sterofoamnya dengan kondisi yang sudah bolong dengan menggunakan alat pembolong lalu kemudian masukkan air ke dalam sterofoam tersebut, airnya cukup setengah saja dan jangan sampai lebih atau penuh. Lalu dimasukkan nutrisinya dengan menggunakan tutup botol (nutrisi A\&B, perbandingan 1:1).
Kemudian ukur PPM nya dari 700 (kalo misalnya kelebihan bisa ditambahkan air lagi untuk menurunkan PPM) dan masukkan semaian ke dalam netpot yang telah disiapkan (dengan flanel yang sudah terpasang).

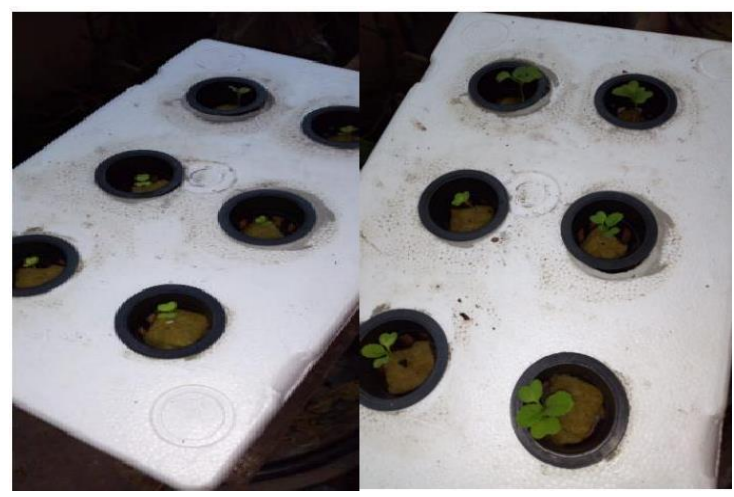

Gambar 4. Perkembangan Benih di Minggu Kedua Peserta Lomba

Pada minggu ketiga, para peserta menaikkan PPM dari PPM 700 menjadi 1000 agar pertumbuhan tanamannya semakin baik. Tanaman sebaiknya dijaga dengan baik dan diletakkan di tempatyang aman jangan sampai kena air hujan atau dimakan tikus.

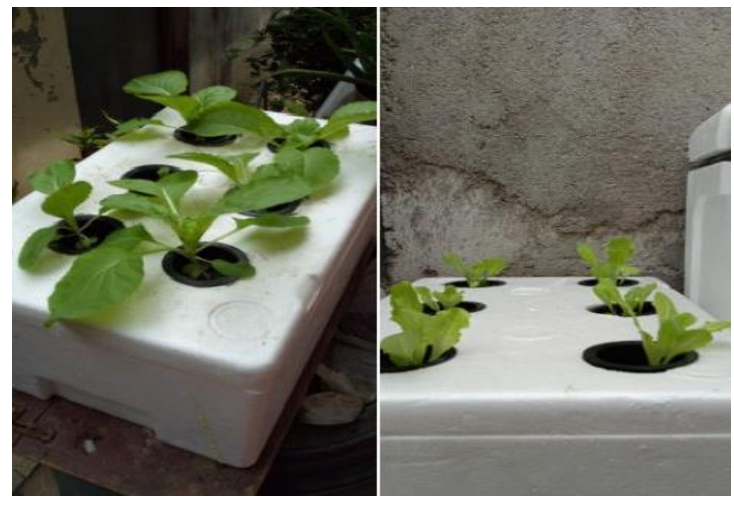

Gambar 5. Perkembangan Benih di Minggu Ketiga Peserta Lomba

Pada minggu keempat, para peserta diarahkan untuk menaikkan PPM dari PPM 
Volume 3, Nomor 1, Tahun 2021 Hal 508 - 516

1000 menjadi1200 sehingga pertumbuhan tanamannya tetap baik. Tanaman pun diarahkan kembali untuk dijaga dengan baik dan diletakkan di tempat yang aman jangan sampai kena air hujan atau dimakan tikus.

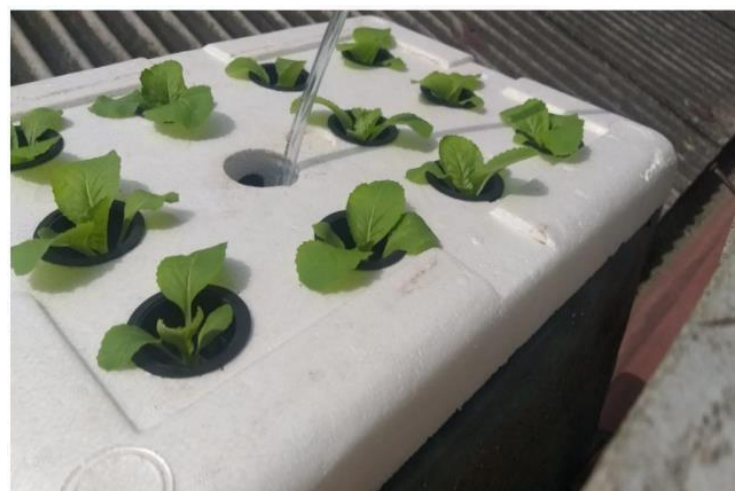

Gambar 6. Perkembangan Benih di Minggu Keempat Peserta Lomba

Pada minggu kelima, para peserta lomba diarahkan untuk memanen hasil tanamannya lalu kemudian dikemas semenarik mungkin agar diberi penilaian oleh juri. Adapun penilaian juri berdasarkan empat (4) kriteria diantaranya tingkat kerapian dari alat dan media tanam, perkembangan sayur yang ditanam, bobot sayuran yang dihasilkan hingga kemasan sayuran tersebut. Penjurian dilakukan oleh tim pelaksana Kegiatan Pengabdian Pada Masyarakat.

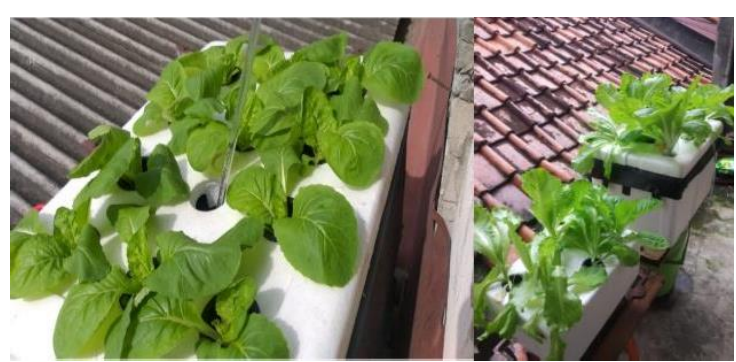

Gambar 7. Perkembangan Benih di Minggu Kelima Peserta Lomba

Pemenang lomba tersebut dinilai berdasarkan empat (4) kriteria diantaranya tingkat kerapian dari alat dan media tanam, perkembangan sayur yang ditanam, bobot sayuran yang dihasilkan hingga kemasan sayuran tersebut. Berikut adalah dokumentasi dari hasil panen para peserta lomba.

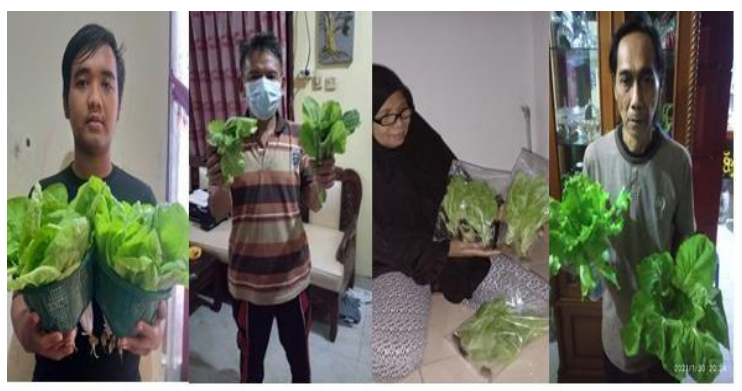

Gambar 8. Hasil Panen yang Dikemas Peserta Lomba

Setelah para peserta melakukan hasil panen, maka diadakan Pengumuman Lomba Kresi Tanaman Hidroponik di RW 09, Kelurahan Kebon Pala Kota Adminitrasi Jakarta Timur pada tanggal 6 februari 2021 melalui via microsoft teams. Berikut adalah hasil dari penilaian para peserta oleh para juri : 


\begin{tabular}{|c|c|c|c|c|c|c|}
\hline \multirow[b]{2}{*}{ Nama } & Kelompok1 & Kelonpok2 & Kelompok3 & Kelompok 4 & Kelampok5 & Kelompok 6 \\
\hline & [Slame Riyation) & Mutamand Arfigritio & (Dinaseb) & (Youbl lahyud) & (Svpam) & Mutjono Joko Tunarito) \\
\hline Pak Bambang & 63 & 80 & 79.5 & \begin{tabular}{|l|}
7925 \\
\end{tabular} & 79 & 625 \\
\hline BuUf & 60 & 7875 & 7625 & 825 & 8125 & 60 \\
\hline Ka Gince & 60 & 7625 & 70 & 75 & 775 & 60 \\
\hline Tyas & 7625 & 795 & 7625 & 77 & 77 & $\pi 7$ \\
\hline Rein & 60 & 8175 & 775 & 8125 & 81 & 60 \\
\hline Aieng & 70 & 7375 & 7625 & 80 & 75 & 70 \\
\hline \multirow[t]{3}{*}{ Eni } & 6375 & 725 & 80 & 7625 & 75 & 65 \\
\hline & 6471228571 & 775 & 7655371129 & 7875 & 7796428571 & 6492857143 \\
\hline & 6 & 3 & 4 & 1 & 2 & 5 \\
\hline
\end{tabular}

\section{Gambar 9. Hasil Penilaian Peserta Lomba}

Setelah mengumpulkan hasil penilaian, maka diumumkan pemenang oleh moderator dimana pemenangnya adalah Juara 1 oleh Bapak Yudi Wahyudi, Juara 2 oleh Ibu Suparmi, Juara 3 oleh Bapak Muhamad Ardianto, Juara Favorit oleh Bapak Djunaedi, Juara Harapan 1 oleh Bapak Mujiyono Joko Turyanto, Juara Harapan 2 oleh Bapak Slamet Riyanto. Para Peserta mendapatkan hadiah uang tunai yang di transfer langsung ke masingmasing rekening para peserta, sertifikat dan goody bag yang dikirimkan melalui jne. Kegiatan ini juga diliput oleh media online CatalogPro.

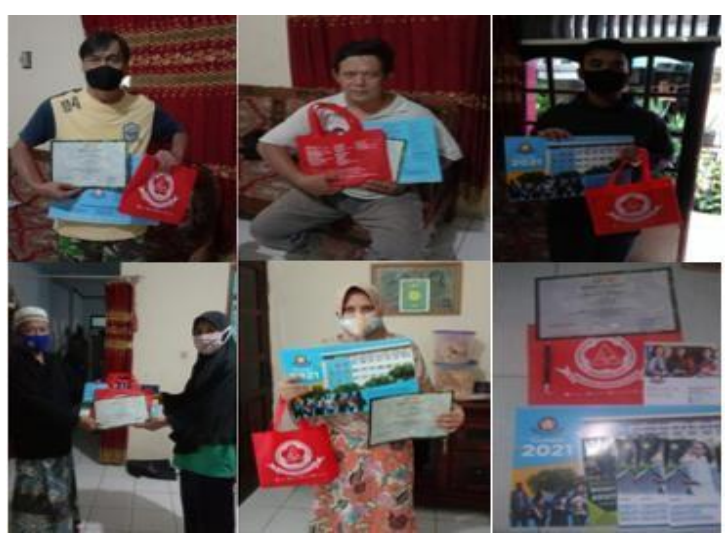

Gambar 10. Pembagian Sertifikat dan Goodybag kepada Para Peserta Lomba

\section{SIMPULAN}

Pengabdian kepada Masyarakat yang berjudul Lomba Kreativitas Tanaman Hidroponik sebagai Strategi dalam Mewujudkan Kampung Hijau di RW 09 Kelurahan Kebon Pala Kota Administrasi Jakarta Timur merupakan kegiatan berkelanjutan yang dilakukan oleh dosen dan mahasiswa di Progra Studi Arsitektur Universitas Kristen Indonesia. Program ini diikuti oleh enam peserta yang berdomisili di RW 09 Kelurahan Kebon Pala Kota Admnistrasi Jakarta Timur yang bertujuan untuk memberikan edukasi mengenai hidroponik dengan mengadakan lomba dengan harapan para peserta lomba melanjutkan kegiatan ini secara mandiri. Kegiatan ini berjalan dengan baik dan mendapat respon positif dari warga yang diharapkan dapat berkelanjutan.

\section{UCAPAN TERIMA KASIH}

Puji dan syukur Penulis panjatkan ke hadirat Tuhan Yang Maha Esa, karena berkat rahmat dan karunia-Nya Penulis dapat menyelesaikan seluruh proses penyusunan Laporan Program Pengabdian Pada Masyarakat Program Studi Arsitektur Fakultas Teknik UKI di tahun 2020 ini yang berjudul Green Action 22 Lomba Kreativitas Tanaman Hidroponik sebagai Strategi dalam Mewujudkan Kampung Hijau di RW 09 Kelurahan Kebon Pala Kota Administrasi Jakarta Timur 2020. Terimakasih sebesar-besarnya tidak lupa penulis ucapkan ucapkan kepada : 
1. Bapak Dr. Dhaniswara K. Harjono, SH., MH., MBA, sebagai Rektor Universitas Kristen Indonesia.

2. Ibu Ir.Galuh Widati, M.Sc, sebagai Dekan Fakultas Teknik Universitas Kristen Indonesia.

3. Bapak Ir.Sahala Simatupang, MT, sebagai Ketua Program Studi Arsitektur Universitas Kristen Indonesia.

4. Bapak Lurah Kelurahan Kebon Pala Kota Administrasi Jakarta Timur 2020 yaitu Bapak Ir.Faisal Rizal, M.Kes

5. Tim Pelaksana Pengabdian pada Masyarakat : Ibu Ulinata, ST.Ars., MT, Bapak Ir.Bambang Erwin, MT, Bapak Ir. Riyadi Ismanto, M.Arch, Grace Putri Dianty, ST., M.Ars.

6. Mahasiswa yang ikut serta yaitu Ajeng Evita Dewi Hasugian, Enrique Keenan Kidingallo, Rein Vikaris Panggalo, Regina Tyas Awangsari Nastiti

7. Penduduk rw 09 di Kelurahan Kebon Pala, Kota Administrasi Jakarta Timur khususnya Para Peserta Lomba yang sudah meluangkan waktu dan tenaganya untuk mengikuti Lomba Kreativitas Tanaman Hidroponik sebagai Strategi dalam Mewujudkan Kampung Hijau di RW 09 Kelurahan Kebon Pala Kota Administrasi Jakarta Timur 2020
8. Bapak Rohedi yang telah berkenan untuk membantu koordinasi kepada Kelurahan dan Para Peserta.

9. Rekan Dosen Program Studi Arsitektur Fakultas Teknik UKI yang berpartisipasi untuk mendukung Program Pengabdian Pada Masyarakat Program Studi Arsitektur Fakultas Teknik UKI di tahun 2020 ini yang berjudul Green Action 22 Lomba Kreativitas Tanaman Hidroponik sebagai Strategi dalam Mewujudkan Kampung Hijau di RW 09 Kelurahan Kebon Pala Kota Administrasi Jakarta Timur 2020.

10. CatalogPro yang sudah meliput dan mempublish ke media online CatalogPro dalam kegiatan Program Pengabdian Pada Masyarakat Program Studi Arsitektur Fakultas Teknik UKI di tahun 2020 ini yang berjudul Green Action 22 Lomba Kreativitas Tanaman Hidroponik sebagai Strategi dalam Mewujudkan Kampung Hijau di RW 09 Kelurahan Kebon Pala Kota Administrasi Jakarta Timur 2020.

11. Semua pihak yang tidak dapat disebutkan satu per satu karena telah berpartisipasi untuk mensukseskan Program Pengabdian Pada Masyarakat ini.

Semoga artikel kegiatan Program Pengabdian kepada Masyarakat ini dapat bermanfaat bagi kita semua khususnya di lingkungan Program Studi Arsitektur Fakultas Teknik UKI. 


\section{REFERENSI}

Mulasari, S. A. (2019). Penerapan Teknologi Tepat Guna (Penanam Hidroponik Menggunakan Media Tanam) Bagi Masyarakat Sosrowijayan Yogyakarta. Jurnal Pemberdayaan: Publikasi Hasil Pengabdian Kepada Masyarakat, 2(3), 425-430.

Ningsih, E., Budianto, A., Udyani, K., \& Julaika, S. (2020). Pemberdayaan Pemberdayaan Karang Taruna Desa Gampingrowo dengan Pelatihan Hidroponik. Dinamisia: Jurnal Pengabdian Kepada Masyarakat, 4(2), 333-338.

Roidah, I. S. (2015). Pemanfaatan lahan dengan menggunakan sistem hidroponik. Jurnal Bonorowo, 1(2), 4349.

Siahaan, U., \& Eni, S. P. (2019). PENGURANGAN VOLUME SAMPAH DENGAN MEMANFAATKAN DAN MENDAUR ULANG SAMPAH MELALUI KEGIATAN PEMBUATAN PUPUK ORGANIKKOMPOS. JURNAL ComunitÃ Servizio: Jurnal Terkait Kegiatan Pengabdian kepada Masyarakat, terkhusus bidang Teknologi, Kewirausahaan dan Sosial Kemasyarakatan, 1(1), 1-10.
Swastika, S., Yulfida, A., \& Sumitro, Y. (2018). Buku Petunjuk Teknis Budidaya Sayuran Hidroponik (Bertanam Tanpa Media Tanah). Riau (ID): Balai Pengkajian Teknologi Pertanian (BPTP) Balitbangtan Riau, Badan Penelitian dan Pengembangan Pertanian, Kementerian Pertanian. 